\title{
The hippocampus supports encoding of between-domain associations within working memory
}

\author{
Carinne Piekema, ${ }^{1,2,6,7}$ Roy P.C. Kessels, ${ }^{2-4}$ Mark Rijpkema, ${ }^{2}$ and Guillén Fernández ${ }^{2,5}$ \\ ${ }^{1}$ Helmholtz Institute, Utrecht University, Utrecht 3508 TC, The Netherlands; ${ }^{2}$ Radboud University Nijmegen, Donders Institute \\ for Brain, Cognition and Behaviour, Nijmegen $6500 \mathrm{HE}$, The Netherlands; ${ }^{3}$ Radboud University Nijmegen Medical Centre, \\ Department of Geriatric Medicine, Nijmegen 6500 HB, The Netherlands; ${ }^{4}$ Department of Medical Psychology, Nijmegen 6500 HB, \\ The Netherlands; ${ }^{5}$ Department of Neurology, Nijmegen $6500 \mathrm{HB}$, The Netherlands
}

\begin{abstract}
It has been established that the medial temporal lobe, including the hippocampus, is crucial for associative memory. The aim of the current functional magnetic resonance imaging (fMRI) study was to investigate whether the hippocampus is differentially activated for associations between items processed in the same neocortical region (within-domain) as compared with associations between items processed in different neocortical regions (between-domain). Here, we show that the hippocampus is significantly more active for between-domain associations compared with within-domain associations. Thus, the hippocampus is important for associative encoding, and furthermore, shows greater activation when the stimuli to be associated come from different stimulus categories.
\end{abstract}

It has become clear that the medial temporal lobe (MTL) plays a key role in memory, but the exact contribution is a matter of extensive debate (Scoville and Milner 1957; Squire et al. 1992, 2007; Eichenbaum et al. 1994; Ranganath and Blumenfeld 2005; Clark et al. 2007). Previously, we have demonstrated that involvement of MTL in associative working memory depends on the type of material that has to be associated. Comparison between spatial and nonspatial associations showed significant hippocampal activation for associations containing spatial information. Since anatomical, physiological, lesion, and imaging studies have long demonstrated a separation in brain regions involved in the processing of spatial information and object processing (e.g., DeYoe and Van Essen 1988; Colby and Goldberg 1999) and in line with the profound role of the hippocampus in spatial memory (O'Keefe and Nadel 1978; Kessels et al. 2001; Burgess et al. 2002; Piekema et al. 2006), we concluded that the presence of a spatial component modulated the activation in the hippocampus (Piekema et al. 2006). However, a more process-oriented explanation could be that the hippocampus was activated as a result of the binding of two items that are each processed in distinct neural modules across the brain (Paller 1997; Piekema et al. 2006). Thus, if associations have to be established between items that are processed in distinct neural structures, the hippocampus may be crucial for binding these items (Paller 1997; Eichenbaum et al. 2007; Mayes et al. 2007). Here we examine the hypothesis that the hippocampus is more important for the association of information processed in different neocortical regions (between-domain) compared with information processed within the same neocortical region (within-domain).

Nineteen right-handed healthy students (three males, age range 18-31 yr, mean $23 \mathrm{yr}, 1-5 \mathrm{yr}$ university education) without a neurological or psychiatric history and normal or corrected-to-

6resent address: Oxford University, Department of Experimental Psychology, Oxford OX1 3UD, UK.

${ }^{7}$ Corresponding author.

E-mail carinne.piekema@psy.ox.ac.uk; fax 44-1865-310447.

Article is online at http://www.learnmem.org/cgi/doi/10.1101//m.1283109. normal vision participated in the experiment. All participants provided written informed consent according to institutional guidelines of the local ethics committee (CMO region ArnhemNijmegen, Netherlands).

During scanning, participants lay supine in the scanner. Visual stimuli were presented on a black background. Responses were recorded via a compatible keypad. Participants performed a three-pair delayed-match-to-sample task (Sternberg 1966) in which three screens, each depicting two stimuli, were presented serially (two houses [within-domain1], two faces [within-domain2], and a face and a house [between-domain], see Fig. 1). Each pair was presented for $2.5 \mathrm{sec}$. Trial-unique photos of houses (visual angle $\sim 6^{\circ}$ ) and faces $\left(\sim 6^{\circ}\right)$ were used as stimuli and presented in grayscale left and right of the center of the screen. The face photographs showed close-ups of adult male faces with direct gaze and neutral facial expression. The house photographs were close-ups of modern day homes.

Following a jittered delay (8-20 sec, uniform distribution), the probe was presented in grayscale left and right of the center of the screen ( 2 sec; Fig. 1). This could either be a repetition of a combination presented in the stimulus set ( $~ 50 \%$ of the time), or a recombination of any two stimuli that were not presented together in the stimulus set. Participants were instructed to indicate by button press whether the combination shown in the probe was a match from the stimulus set (right index finger) or not (right middle finger). The intertrial interval (ITI) varied between 3 and $5 \mathrm{sec}$ (uniform distribution). Forty trials per condition were presented randomly intermixed. Unique stimulus lists were created for each participant, randomizing house and face "identity," as well as delay and ITI lengths. A training session using a different set of stimuli was performed outside the scanner. Participants were instructed to prioritize correct responding over speed.

Whole head T2*-weighted EPI-BOLD fMRI data were acquired with a Siemens 3T MR-scanner (37 axial slices, ascending acquisition, $\mathrm{TR}=2.18 \mathrm{sec}$, $\mathrm{TE}=25 \mathrm{msec}, 80^{\circ}$ flip-angle, $64 \times 64$ matrix, 3.0-mm slice thickness, $0.5-\mathrm{mm}$ gap, $212-\mathrm{mm}$ field-of-view). Structural scans were acquired, using a T1-weighted MP-RAGE sequence $\left(\mathrm{TR}=2250 \mathrm{msec}, \mathrm{TE}=3.93 \mathrm{msec}, 15^{\circ}\right.$ flip-angle, 176 

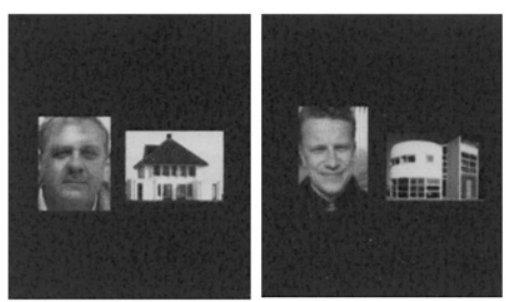

Stimulus set $7.5 \mathrm{~s}$
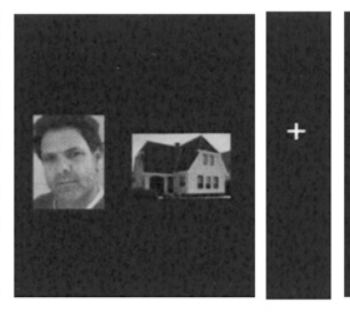

Delay 8-20s

Figure 1. Experimental design. This figure depicts an example of the between-domain association condition. During the delay, participants had to maintain the combination of each item pair presented in the stimulus set. Following the delay, a probe was presented and the participant had to indicate whether the probe was a match from the stimulus set or not. Trials were separated by a variable intertrial interval (ITI).

sagittal slices, $256 \times 256$ matrix, $1 \mathrm{~mm}$, slice thickness, $0.5-\mathrm{mm}$ gap, 256-mm field-of-view).

The first five volumes of each data set were discarded to allow for T1 equilibration. Image preprocessing and statistical analysis was performed using SPM5 (www.fil.ion.ucl.ac.uk/spm). Functional images were spatially realigned, after which the participant's structural image was coregistered to the mean of the functional images, using mutual information optimization. Subsequently, functional images were slice-time corrected, spatially normalized, and resampled to create 2-mm isotropic voxels, transformed into a common stereotactic space (MNI T1 template), and spatially filtered by convolving the functional images with an isotropic 3D Gaussian kernel (FWHM: $8 \mathrm{~mm}$ ). The general linear model and statistical parametric mapping were used for statistical analysis (Friston et al. 1995a,b). For each condition (withindomain1; within-domain2; between-domain), separate regressors were created for stimulus-set presentation, delay interval, and probe- and response-related effects. Separate regressors were created for correct and incorrect trials. To account for movementrelated variability, realignment parameters were included in the model. Data were high-pass filtered $(128 \mathrm{sec})$ to account for various low-frequency effects. Temporal autocorrelation was modeled as an $\mathrm{AR}(1)$ process. Unless otherwise specified, activations reported are thresholded at $P<0.05$ corrected for multiple nonindependent comparisons based on the false discovery rate (FDR) (Worsley et al. 1996). All clusters of activations are described by an anatomical label and the local maximum (MNI-coordinate with $t$-value and $P$-level).

Participants performed significantly above chance level (50\%) in all conditions (1) within-domain1: mean correct $70 \%$ (SD 9.8\%), $t_{(16)}=8.3, P<0.0001$, (2) within-domain2: mean correct $73 \%$ (SD9.6\%), $t_{(16)}=9.7, P<0.0001$, and (3) betweendomain: mean correct $73 \%$ (SD13.3\%), $t_{(16)}=7.0, P<0.0001$. Two subjects were discarded from further analysis because their overall performance was at chance level. The repeated measures analysis of variance-comparing means of the three different conditions did not reveal any main effect $\left(F_{(1,16)}=0.988, P<0.335\right)$, suggesting that performance did not differ between conditions allowing us to collapse the two within-domain conditions for imaging analyses.

To test whether our setup did evoke differential activation for the two object categories (faces and houses), we compared activations related to the presentation of house and face stimuli. Activations for house stimuli were observed in the parahippocampal gyrus (PHG) bilaterally (local maximum: [18 $-44-10], t_{(16)}=$ 11.82, $P_{\text {corr }}<0.0001$; local maximum: $[-22-46-8], t_{(16)}=10.24$, $P_{\text {corr }}<0.0001$ ), right inferior parietal lobe (local maximum: [34-4656], $\left.t_{(16)}=4.36, P_{\text {corr }}=0.004\right)$, left middle frontal gyrus (local maximum: $\left[\begin{array}{lll}-30 & 0 & 52\end{array}\right], t_{(16)}=3.81, P_{\text {corr }}=0.006$ ), cingulate

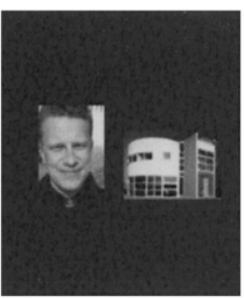

Probe

2s

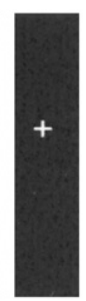

ITI

$3-5 s$ the fusiform gyrus was activated at all.
fusiform gyrus was observed at $P=0.002$

gyrus (local maximum: [4 -2630$], t_{(16)}=$ 4.95, $\left.P_{\text {corr }}=0.002\right)$, left postcentral gyrus (local maximum: $[-58-1830], t_{(16)}=$ $3.36, P_{\text {corr }}=0.012$ ), right superior temporal gyrus (local maximum: [70 -18 8], $\left.t_{(16)}=4.44, P_{\text {corr }}=0.003\right)$, and right inferior temporal gyrus (local maximum: $\left.[60-56-10], t_{(16)}=3.37, P_{\text {corr }}=0.019\right)$.

For the face stimuli we did not observe any activation when applying a threshold of $P<0.05$ FDR corrected. However, given the well-established role for the fusiform gyrus in face processing, we did expect to find activation in this region. Therefore, we applied a more lenient threshold of $P<0.005$ uncorrected for multiple comparisons to test whether Activation in the right fusiform gyrus was observed at $P=0.002$
uncorrected for multiple comparison (local maximum: [46 -36 -18 ], $t_{(16)}=3.31, P=0.002$ ). Other activations observed at this more lenient, uncorrected threshold were middle frontal gyrus (local maximum: [46 446], $t_{(16)}=3.58, P=0.001$ ), middle temporal gyrus (local maximum: $[38-6216], t_{(16)}=5.41, P<0.0001$ ), superior frontal gyrus (local maximum: [8 10 64], $t_{(16)}=3.83, P=$ 0.001 ), superior temporal gyrus (local maximum: [54 26 10], $t_{(16)}=$ $7.10, P<0.0001$ ), middle occipital gyrus (local maximum: [48 -74 $4], t_{(16)}=4.27, P<0.0001$ ), precuneus (local maximum: [0 -54 40], $t_{(16)}=4.25, P<0.0001$ ), and amygdala bilaterally (local maximum: $[22-6-16], t_{(16)}=3.98, P=0.001$; local maximum: $[-20-10$ $\left.-16], t_{(16)}=5.13, P=0.003\right)$. Additional analysis focused on the delay period of within-domain and between-domain associations together (correct trials only) against a visual fixation baseline. This revealed a variety of regions commonly associated with active working memory maintenance (i.e., specific parietal, temporal,

Table 1. Regions showing delay-related activation of both within-domain and between-domain associations together (correct trials only) against a low-level visual fixation baseline

Within-domain + Between-domain > Implicit baseline (delay)

\begin{tabular}{lccccc}
\hline & \multicolumn{3}{c}{ MNI Coordinates } & & \\
\cline { 2 - 4 } & $x$ & $y$ & $Z$ & $T$ value & $\begin{array}{c}\text { Number } \\
\text { of voxels }\end{array}$ \\
\hline Anatomical region & 14 & 36 & 46 & 5.70 & 817 \\
\hline $\begin{array}{l}\text { Right middle frontal } \\
\text { gyrus (BA10) }\end{array}$ & 22 & 36 & 36 & 5.43 & \\
$\begin{array}{l}\text { Right superior frontal } \\
\text { gyrus (BA9) }\end{array}$ & -18 & 46 & 0 & 5.49 & 349 \\
$\begin{array}{l}\text { Left superior frontal } \\
\quad \text { gyrus (BA10) }\end{array}$ & -4 & 30 & 4 & 5.28 & \\
$\begin{array}{l}\text { Anterior cingulate } \\
\quad \text { BA24) }\end{array}$ & -6 & 24 & -14 & 4.70 & \\
$\begin{array}{l}\text { Left medial frontal } \\
\text { gyrus (BA11) }\end{array}$ & -16 & 32 & 32 & 5.34 & 609 \\
$\begin{array}{l}\text { Left medial frontal } \\
\text { gyrus (BA9) }\end{array}$ & -18 & 24 & 46 & 5.18 & \\
$\begin{array}{l}\text { Left middle frontal } \\
\text { gyrus (BA8) } \\
\text { Left superior frontal } \\
\text { gyrus (BA8) }\end{array}$ & 64 & -10 & -14 & 5.28 & 301 \\
$\begin{array}{l}\text { Right inferior temporal } \\
\quad \text { gyrus (BA21) }\end{array}$ & 60 & -24 & -2 & 4.53 & \\
$\begin{array}{l}\text { Right superior temporal } \\
\text { gyrus (BA21) }\end{array}$ & & & & & \\
\hline
\end{tabular}

All clusters listed are significant at $P<0.05$ (FDR corrected for multiple comparisons). 
and frontal regions) (for review, see Wager and Smith 2003) (see also Table 1).

To investigate the question at issue, contrast images of encoding-related effects on correct trials only were created and entered into a second-level analysis. Simple $t$-contrasts were used to test differences in activations for within-domain and betweendomain associations. Activations related to the contrasts "withindomain vs. between-domain" and "between-domain vs. withindomain" are shown in Table 2 and Figure 2 . The contrast "betweendomain vs. within-domain" revealed a set of activations in the right hippocampus (local maximum: [26 -16 -16], $t_{(16)}=4.13$, $P_{\text {corr }}=0.019$ ), parahippocampal gyrus bilaterally (local maximum: $[34-32-16], t_{(16)}=4.59, P_{\text {corr }}=0.011$; local maximum: $[-26-20$ $-16], t_{(16)}=3.78, P_{\text {corr }}=0.028$ ), left superior frontal gyrus (local maximum: $\left.\left[\begin{array}{lll}-16 & 48 & 38\end{array}\right], t_{(16)}=5.08, P_{\text {corr }}=0.006\right)$, precuneus extending into posterior cingulate cortex (local maximum: [2 -64 $20], t_{(16)}=11.51, P_{\text {corr }}<0.0001$ ), left superior occipital gyrus (local maximum: $\left.[-32-9026], t_{(16)}=8.54, P_{\text {corr }}=0.001\right)$, and fusiform gyrus bilaterally (local maximum: [36 $-38-10], t_{(16)}=10.74, P_{\text {corr }}$ $<0.0001$; local maximum: $[-26-44-10], t_{(16)}=8.57, P_{\text {corr }}=$

Table 2. Differential activation related to the contrasts "between-domain vs. within-domain"

\begin{tabular}{|c|c|c|c|c|c|}
\hline \multicolumn{6}{|c|}{ Between-domain $>$ Within-domain (encoding) } \\
\hline \multirow[b]{2}{*}{ Anatomical region } & \multicolumn{3}{|c|}{ MNI coordinates } & \multirow[b]{2}{*}{$T$ value } & \multirow{2}{*}{$\begin{array}{l}\text { Number } \\
\text { of voxels }\end{array}$} \\
\hline & $x$ & $r$ & $Z$ & & \\
\hline Precuneus (BA23) & 2 & -64 & 20 & 11.51 & 4333 \\
\hline $\begin{array}{l}\text { Right fusiform } \\
\text { gyrus (BA37) }\end{array}$ & 36 & -38 & -10 & 10.74 & \\
\hline $\begin{array}{l}\text { Left fusiform } \\
\text { gyrus (BA37) }\end{array}$ & -26 & -44 & -10 & 8.57 & 609 \\
\hline $\begin{array}{l}\text { Right parahippocampal } \\
\text { gyrus (BA37) }\end{array}$ & 34 & -32 & -16 & 4.59 & \\
\hline $\begin{array}{l}\text { Left parahippocampal } \\
\text { gyrus (BA37) }\end{array}$ & -26 & -20 & -16 & 3.78 & \\
\hline Right hippocampus & 26 & -16 & -16 & 4.13 & \\
\hline Culmen (cerebellum) & -32 & -90 & 26 & 8.54 & 491 \\
\hline $\begin{array}{l}\text { Left superior occipital } \\
\text { gyrus (BA19) }\end{array}$ & -38 & -74 & 30 & 6.93 & \\
\hline $\begin{array}{l}\text { Left inferior frontal } \\
\text { gyrus (BA45) }\end{array}$ & -38 & -26 & 4 & 6.50 & 71 \\
\hline $\begin{array}{l}\text { Middle temporal } \\
\text { gyrus (BA39) }\end{array}$ & -46 & -36 & 0 & 4.49 & \\
\hline Insula (BA22) & -56 & -38 & -2 & 4.21 & \\
\hline $\begin{array}{l}\text { Left superior frontal } \\
\text { gyrus (BA8) }\end{array}$ & -16 & 48 & 38 & 5.08 & 151 \\
\hline $\begin{array}{l}\text { Left lingual } \\
\text { gyrus (BA18) }\end{array}$ & -30 & -70 & -10 & 4.76 & 23 \\
\hline $\begin{array}{l}\text { Left fusiform } \\
\text { gyrus (BA19) }\end{array}$ & -26 & -82 & -12 & 4.76 & 15 \\
\hline $\begin{array}{l}\text { Left inferior occipital } \\
\text { gyrus (BA18) }\end{array}$ & -22 & -90 & -10 & 4.37 & \\
\hline Insula (BA13) & 34 & -22 & 16 & 4.59 & 49 \\
\hline Putamen & 34 & -20 & 6 & 4.18 & \\
\hline $\begin{array}{l}\text { Left middle frontal } \\
\text { gyrus (BA8) }\end{array}$ & -22 & 18 & 44 & 4.42 & 13 \\
\hline $\begin{array}{l}\text { Right cingulate } \\
\text { gyrus (BA31) }\end{array}$ & 18 & -44 & 36 & 4.40 & 17 \\
\hline $\begin{array}{l}\text { Left middle frontal } \\
\text { gyrus (BA46) }\end{array}$ & -40 & 16 & 28 & 4.23 & 11 \\
\hline $\begin{array}{l}\text { Right inferior frontal } \\
\text { gyrus (BA45) }\end{array}$ & 58 & 32 & 6 & 4.16 & 13 \\
\hline $\begin{array}{l}\text { Right middle temporal } \\
\text { gyrus (BA39) }\end{array}$ & 48 & -66 & 30 & 4.14 & 12 \\
\hline Cuneus (BA18) & -10 & -100 & 0 & 3.98 & 5 \\
\hline
\end{tabular}

All clusters listed are significant at $P<0.05$ (FDR corrected for multiple comparisons).
0.001). The opposite contrast (within-domain vs. between-domain) did not reveal any activation at the corrected threshold.

One may suggest that the hippocampal activation observed in the between-domain vs. within-domain contrast is caused by the fact that we are comparing two different types of stimuli. To rule out this possibility, we took the local maximum from the betweendomain vs. within-domain contrast and show the pattern of activation for each condition separately. Figure 2D clearly shows that the hippocampal activation in this contrast is solely driven by the activation in the between-domain condition, ruling out a hippocampal bias based on the type of stimulus used (see Fig. 2D).

Numerous studies have demonstrated that the hippocampus is important for associative long-term memory formation in general. To investigate whether the hippocampus was activated during working memory for within-domain associations as well, we contrasted both within-domain associations against a low-level visual fixation baseline and observed a set of activations including the hippocampus bilaterally (local maximum: [26 -32 2], $t_{(16)}=$ 11.62, $P_{\text {corr }}<0.0001$; local maximum: $\left[\begin{array}{lll}-22 & -30 & -2\end{array}\right], t_{(16)}=$ $11.69, P_{\text {corr }}<0.0001$ ), superior parietal lobes bilaterally (local maximum: $[22-6456], t_{(16)}=14.16, P_{\text {corr }}<0.0001$; local maximum: $[-26-6456], t_{(16)}=8.79, P_{\text {corr }}=0.013$ ) left inferior frontal cortex (local maximum: $\left[\begin{array}{ccc}-42 & 6 & 26\end{array}\right], t_{(16)}=13.27, P_{\text {corr }}$ $<0.0001$ ), fusiform gyrus bilaterally (local maximum: [28 -64 $-12], t_{(16)}=17.56, P_{\text {corr }}<0.0001$; local maximum: [ $\left.-26-62-12\right]$, $t_{(16)}=14.81, P_{\text {corr }}<0.0001$ ), right superior occipital gyrus (local maximum: $\left.[30-7230], t_{(16)}=8.59, P_{\text {corr }}=0.016\right)$, and right precentral gyrus (local maximum: [50 232 3 $, t_{(16)}=8.50, P_{\text {corr }}=$ 0.018). Thus, in line with the importance of the hippocampus in associative memory in general, in this study working memory for within-domain associations did also activate the hippocampus, but to a lesser extent than it did for working-memory encoding of between-domain associations. Therefore, we suggest that the hippocampus is important for associative memory in general, and in our study, shows greater activation when associations are made between items that are not processed in the same neocortical region. Hence, this study confirms the notion coined by Mayes et al. (2007), that the processing of between-domain associations is mediated by the hippocampus, even in working-memory tasks.

Other activations for between-domain vs. within-domain were observed in the superior frontal gyrus, precuneus, and fusiform gyrus. The precuneus activation may be related directly to the hippocampal activation, because this region is closely interlinked with the MTL (Lavenex et al. 2002). Ranganath et al. (2005) have shown a strong functional connectivity between the hippocampus and the precuneus during a working-memory task similar to our design. Hence, the precuneus may represent an interface between classical working-memory areas in the prefrontal cortex and long-term memory areas in the MTL (Kobayashi and Amaral 2003). The activations observed in the fusiform gyrus and parts of the parahippocampal cortex are somewhat surprising, as one might expect to find greater activation in those regions for the within-domain condition, where two houses and two faces are contrasted against just one face and one house in the betweendomain condition. However, this effect might be caused by associative processing between the two domains involved in the between-domain condition. From an anatomical perspective, Lavenex and Amaral (2000) have suggested a hierarchy of integration within the MTL such that, while complete integration of the information only takes place in the hippocampus, a high level of integration (both unimodal and polymodal) is also possible within inferior temporal regions through its strong reciprocal connectivity with other regions within the inferior temporal cortex. We speculate that the complexity of integration required to integrate two different objects (a face and a house) as compared with two similar objects (two faces or two houses) might therefore 

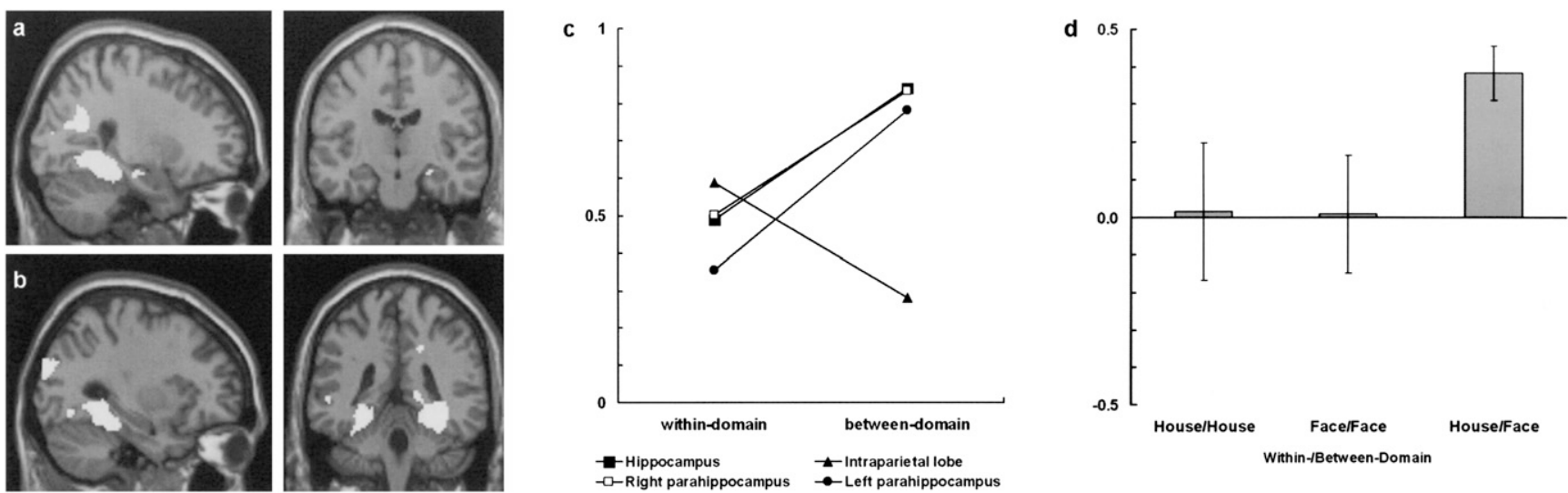

Figure 2. $(A, B)$ The encoding activation related to the contrast between-domain association $>$ within-domain association; $C$ shows the $\beta$ weights (in arbitrary units) averaged over subjects in the four different regions. The coordinates for the different regions were selected (local maxima) from the encoding-related activation for within- and between-domain associations grouped together (hippocampus [30 -22 -12], right PHG [parahippocampal gyrus] [26 -34-17], left PHG [ $-38-20-14]$, and intraparietal lobe [44 -43-45]). For each subject the $\beta$ weights for the different regions were extracted, and for each region an average was made over subjects. (D) Depicts the $\beta$ weights in the hippocampal local maximum [26 -16 16] observed in the between-domain vs. within-domain contrast for each of the three conditions separately: (H-H) House/House; (F-F) Face/Face; (H-F) House/Face.

also increasingly engage the inferior temporal regions in our study. Mayes and colleagues suggested that long-term withindomain associative memory activates the perirhinal cortex (Mayes et al. 2007), but even at a more lenient threshold ( $P<0.01$ uncorrected) we did not observe activity in this region. This result is not entirely surprising as perirhinal activations are mainly found in studies focusing on long-term memory (see Eichenbaum et al. 2007; Mayes et al. 2007). Hence, it might be that our working memory paradigm did not engage the perirhinal cortex in a way similar to associative within-domain processing in long-term memory tasks.

In conclusion, we show that the hippocampus is important for associating items, even in a working-memory task, and furthermore, we show that when comparing between-domain associations and within-domain associations, the hippocampus is significantly more activated when associations are made between items processed normally and items processed in different neocortical regions.

\section{Acknowledgments}

This study was funded by a grant from the Brain Foundation of the Netherlands (No. 13F05.03), awarded to R.P.C.K. We thank Mark Walton for commenting on earlier versions of this manuscript.

\section{References}

Burgess, N., Maguire, E.A., and O'Keefe, J. 2002. The human hippocampus and spatial and episodic memory. Neuron 35: 625-641.

Clark, R.E., Broadbent, N.J., and Squire, L.R. 2007. The hippocampus and spatial memory: Findings with a novel modification of the water maze. I. Neurosci. 27: 6647-6654.

Colby, C.L. and Goldberg, M.E. 1999. Space and attention in parietal cortex. Annu. Rev. Neurosci. 22: 319-349.

DeYoe, E.A. and Van Essen, D.C. 1988. Concurrent processing streams in monkey visual cortex. Trends Neurosci. 11: 219-226.

Eichenbaum, H., Otto, T., and Cohen, N.J. 1994. Two functional components of the hippocampal memory system. Behav. Brain Sci. 17: 449-517.

Eichenbaum, H., Yonelinas, A.P., and Ranganath, C. 2007. The medial temporal lobe and recognition memory. Annu. Rev. Neurosci. 30: $123-152$.

Friston, K.J., Asburner, J., Frith, C.D., Poline, J.B., Heather, J.D., and Frackowiak, R.S. 1995a. Spatial registration and normalization of images. Hum. Brain Mapp. 3: 165-189.
Friston, K.J., Holmes, A.P., Worsley, K., Poline, J.B., and Frackowiak, R.S 1995b. Statistical parametric maps in functional imaging: A general linear approach. Hum. Brain Mapp. 2: 189-210.

Kessels, R.P.C., De Haan, E.H.F., Kappelle, L.J., and Postma, A. 2001. Varieties of human spatial memory: A meta-analysis on the effects of hippocampal lesions. Brain Res. Brain Res. Rev. 35: 295-303.

Kobayashi, Y. and Amaral, D.G. 2003. Macaque monkey retrosplenial cortex: II. Cortical afferents. J. Comp. Neurol. 466: 48-79.

Lavenex, P. and Amaral, D.G. 2000. Hippocampal-neocortical interaction: A hierarchy of associativity. Hippocampus 10: 420-430.

Lavenex, P., Suzuki, W.A., and Amaral, D.G. 2002. Perirhinal and parahippocampal cortices of the macaque monkey: Projections to the neocortex. J. Comp. Neurol. 447: 394-420.

Mayes, A., Montaldi, D., and Migo, E. 2007. Associative memory and the medial temporal lobes. Trends Cogn. Sci. 11: 126-135.

O'Keefe, J. and Nadel, L. 1978. The hippocampus as a cognitive map. Oxford University Press, Oxford, UK.

Paller, K. 1997. Consolidating dispersed neocortical memories: The missing link in amnesia. Memory 5: 73-88.

Piekema, C., Kessels, R.P.C., Mars, R.B., Petersson, K.M., and Fernández, G. 2006. The right hippocampus participates in short-term memory maintenance of object-location associations. Neuroimage 33: 374-382.

Ranganath, C. and Blumenfeld, R.S. 2005. Doubts about double dissociations between short- and long-term memory. Trends Cogn. Sci. 9: 374-380.

Ranganath, C., Heller, A., Cohen, M.X., Brozinsky, C.J., and Rissman, J. 2005. Functional connectivity with the hippocampus during successful memory formation. Hippocampus 15: 997-1005.

Scoville, W.B. and Milner, B. 1957. Loss of recent memory after bilateral hippocampal lesions. J. Neurol. Neurosurg. Psychiatr. 20: 11-21.

Squire, L.R., Ojemann, J.G., Miezin, F.M., Petersen, S.E., Videen, T.O., and Raichle, M.E. 1992. Activation of the hippocampus in normal humans: A functional anatomical study of memory. Proc. Natl. Acad. Sci. 89: 1837-1841.

Squire, L.R., Wixted, J.T., and Clark, R.E. 2007. Recognition memory and the medial temporal lobe: A new perspective. Nat. Rev. Neurosci. 8: 872883.

Sternberg, S. 1966. High-speed scanning in human memory. Science 153: $652-654$.

Wager, T.D. and Smith, E.E. 2003. Neuroimaging studies of working memory: A meta-analysis. Cogn. Affect. Behav. Neurosci. 3: 255-274.

Worsley, K., Marrett, S., Neelin, P., Vandal, A., Friston, K.J., and Evans, A. 1996. A unified statistical approach for determining significant signals in images of cerebral activation. Hum. Brain Mapp. 4: 58-73.

Received November 12, 2008; accepted in revised form December 22, 2008. 


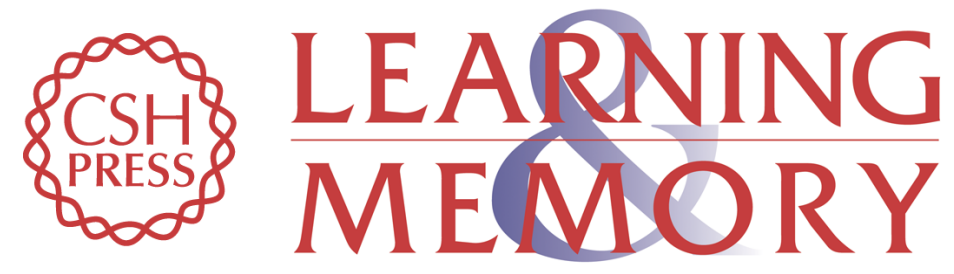

\section{The hippocampus supports encoding of between-domain associations within working memory}

Carinne Piekema, Roy P.C. Kessels, Mark Rijpkema, et al.

Learn. Mem. 2009, 16:

Access the most recent version at doi:10.1101//m.1283109

References This article cites 23 articles, 4 of which can be accessed free at:

http://learnmem.cshlp.org/content/16/4/231.full.html\#ref-list-1

License

Email Alerting Receive free email alerts when new articles cite this article - sign up in the box at the Service top right corner of the article or click here. 